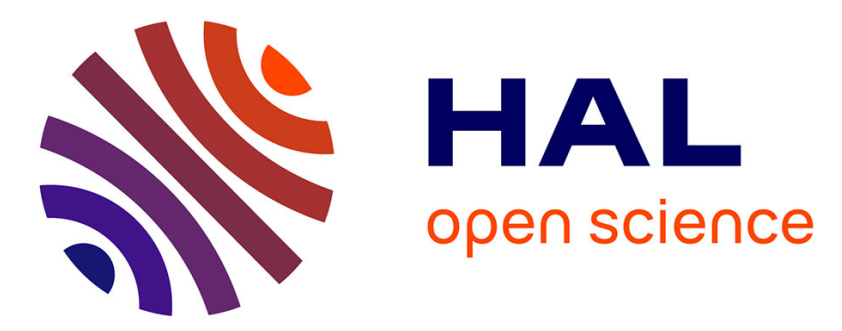

\title{
A 3D effect in the wedge adhesion test : application of speckle interferometry
}

Sylvain Popineau, Benoît Gautier, Pierre Slangen, Martin E.R. Shanahan

\section{To cite this version:}

Sylvain Popineau, Benoît Gautier, Pierre Slangen, Martin E.R. Shanahan. A 3D effect in the wedge adhesion test: application of speckle interferometry. Journal of Adhesion, 2004, 80, pp.1173 - 1194. 10.1080/00218460490884349. hal-00142198

\section{HAL Id: hal-00142198 https://hal.science/hal-00142198}

Submitted on 18 Aug 2021

HAL is a multi-disciplinary open access archive for the deposit and dissemination of scientific research documents, whether they are published or not. The documents may come from teaching and research institutions in France or abroad, or from public or private research centers.
L'archive ouverte pluridisciplinaire HAL, est destinée au dépôt et à la diffusion de documents scientifiques de niveau recherche, publiés ou non, émanant des établissements d'enseignement et de recherche français ou étrangers, des laboratoires publics ou privés. 


\title{
A 3D EFFECT IN THE WEDGE ADHESION TEST: APPLICATION OF SPECKLE INTERFEROMETRY
}

\author{
Sylvain Popineau \\ Ecole des Mines de Paris, Centre des Matériaux P. M. Fourt, \\ Evry Cedex, France

\section{Benoît Gautier \\ Pierre Slangen \\ Martin E. R. Shanahan} \\ Ecole des Mines d'Alès, Centre des Matériaux (CMGD), \\ Ales Cedex, France
}

\begin{abstract}
The wedge test is of considerable use for evaluating adhesion between two bonded rigid substrates. In its (usual) static form, release of elastic strain energy is equated to effective adhesion energy during crack growth. However, the test is usually treated as two-dimensional. In fact, it is really three-dimensional due to anticlastic bending effects of the bent beam(s) during crack propagation.

We studied a composite material/epoxy/aluminium alloy system and observed a curved crack front during propagation. This leads to doubt as to the value of crack length to be inserted in the adhesion energy formula. In addition, by using the highly sensitive technique of speckle interferometry, it was possible to study anticlastic bending effects in a quantitative manner. Far from the crack front, agreement between theory and experimental is good, yet work remains to be done to understand the zone near the fracture zone.
\end{abstract}

Keywords: Aluminium; Anticlastic bending; Cleavage; Composite; Epoxy; Speckle Interferometry; Wedge test

The authors thank the DGA and SNECMA Bordeaux for financial and material support. Enthusiastic discussions with Sébastien Courmont from the latter establishment have been greatly appreciated. 


\section{INTRODUCTION}

The adhesion of two solids, whether by the intermediary of an adhesive or not, is usually assessed by some sort of destructive test leading to separation. Although stress at failure can give useful, pragmatic data for industrial uses and comparison of, for example, the relative efficiency of different surface treatments prior to bonding, assessment of fracture energy is often more informative. This fracture energy, or effective energy of adhesion, or critical energy release rate (three terms for essentially the same quantity) can be efficiently measured by tests such as peel when at least one of the adherends is sufficiently flexible. However, when the substrates are relatively rigid, and not prone to bending, experimental methods are generally more complex, the classic example being the double cantilever beam (DCB), as first suggested by Benbow and Roesler in the 1950s [1] and much developed since [2-5].

A variant of the DCB is the wedge test, sometimes referred to as the Boeing wedge test [6], which in its symmetrical form corresponds to two identical sheets of elastic - but relatively high modulus-material bonded together along faces of the largest surface area, except at one extremity. A wedge is inserted into this unbonded section, forcing the adherends to bend away from the plane of symmetry. If the system is left in this state, a crack in, or near, the adhesion zone starts to grow, the motive power coming from the restitution of stored elastic energy of the curved substrates becoming less curved as the crack becomes longer. The asymmetric version of this setup is shown in Figure 1, which corresponds to the case that we shall be treating below: instead

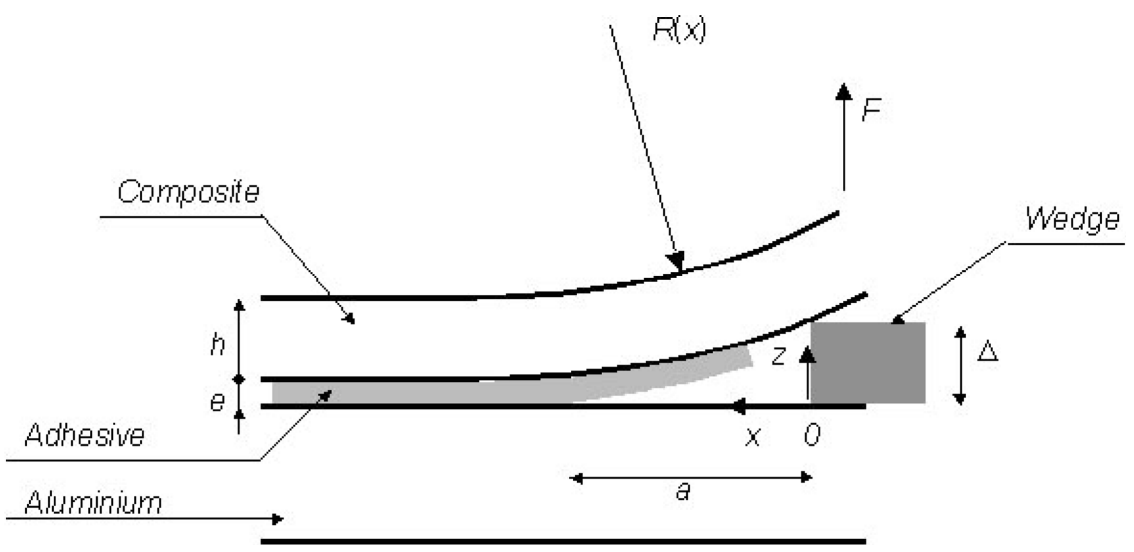

FIGURE 1 Schematic representation of wedge test with one flexible beam. 
of two identical elastic adherends, we shall treat the case of one adherend being, for all intents and purposes, infinitely rigid, although the basis of the principle is the same. In the symmetrical case, analysis of the energy release rate and crack growth leads to the classic wedge, or cleavage, formula [7, 8]:

$$
G_{I C}=\frac{3 E \Delta^{2} h^{3}}{16 a^{4}},
$$

where $\mathrm{G}_{\mathrm{IC}}$ is the critical elastic energy release rate, which may be identified with global adhesive energy (breaking of interfacial bonds, plus associated energy dissipation due to high, local strain near the separation tip); $\mathrm{E}$ is the Young's modulus of the adherend, or beam material; $\Delta$ is the wedge thickness; $h$ is the beam thickness; and $a$ is the crack length taken from the position of the wedge to the crack front.

Apart from applying to the symmetrical case, Equation (1) is obtained from a two-dimensional (2D) analysis of the system, ignoring any potential dependence on bond width, $b$, (direction perpendicular to the figure).

If the system is asymmetric, with dissimilar adherends, in principle the term $\mathrm{G}_{\mathrm{IC}}$ should be replaced by some suitable function of $\mathrm{G}_{\mathrm{IC}}$ and $\mathrm{G}_{\mathrm{IIC}}$, where I and II refer to the classic failure modes [9]. This aspect will not be treated here. Whether the system is symmetrical or not, another effect has generally been overlooked: the system is in reality three-dimensional (3D) and not two-dimensional. If one bends a rectangular-rubber eraser, a radius of curvature, $\mathrm{R}$, will be observed. Further inspection shows another curvature, of radius $\rho$, perpendicular to the first and in the opposite direction. This is the well-known effect of anticlastic bending [10], such that:

$$
\rho=R / v,
$$

where $v$ is Poisson's ratio of the elastomer. This effect may be important for the wedge test, and it corresponds to the central theme of this article. We considered the adhesion of a phenolic resin-based composite to aluminium using an epoxy adhesive. The asymmetric wedge test was adopted for the investigation of adhesion properties. Optical techniques, specifically speckle interferometry, were exploited to consider the detailed deformation of the system during crack growth.

\section{EXPERIMENTAL}

\section{Materials}

Asymmetric wedge test assemblies were made from aluminium alloy (Young's modulus, $\mathrm{E}=70 \mathrm{GPa}$; Poisson's ratio, $v=0.33$ ) blocks of 
dimensions $150 \times 25 \mathrm{~mm}^{2}, 5 \mathrm{~mm}$ thick, bonded to a $2 \mathrm{D}$, carbon-fibre filled resin composite (Young's modulus, $\mathrm{E}=17 \mathrm{GPa}$; Poisson's ratio, $v=0.08$ ) blocks of dimensions $150 \times 25 \mathrm{~mm}^{2}, 4 \mathrm{~mm}$ thick, using a supple epoxy adhesive (EC2216, 3 M Co., St. Paul, MN, USA; Young's modulus $=c a .400 \mathrm{MPa}$ ). Curing conditions were 7 days at $23^{\circ} \mathrm{C}$ in ambient conditions of humidity and pressure in a regulated oven. All samples were dried at $40^{\circ} \mathrm{C}$ and $20 \%$ relative humidity $(\mathrm{RH})$ in a drying oven over a period of 3 weeks before testing.

Surface treatment of the aluminium was restricted to grit-blasting (700 micron corundum), ultrasonic cleaning in acetone for $1 \mathrm{~min}$ and solvent degreasing using ethanol, followed by drying at $40^{\circ} \mathrm{C}, 25 \% \mathrm{RH}$ for $1 \mathrm{~h}$. Composite pretreatment was limited to solvent degreasing with methyl ethyl ketone using a soft cloth.

At one end of the assembly a steel spacer sprayed with antiadhesive silicone was added between composite and aluminium to avoid local adhesion.

\section{Wedge Test}

Composite/epoxy/aluminium assemblies were mounted on a jig attached to an Instron tensile tester (Model TT-DM, Instron, High Wycombe, UK). A steel "wedge" or blade of thickness $0.6 \mathrm{~mm}$ was inserted into the nonadhering end of the system to initiate crack growth by bending the composite. The blade was inserted to a depth of $12 \mathrm{~mm}$. The wedge was stopped just before reaching the adhesive joint. This technique permits an accurate estimation of the distance between the aluminium and the composite adherends at the blade edge.

Measurements of crack length, $a$, as a function of time were made either by direct estimation of separation depth, as observed from the side(s) of the sample, or by measurement of visual effects of compression on a millimetric scale adhering to the polished external surface of the composite beam, for the most part. In addition, specific experiments were conducted using speckle interferometry as described below. The geometry of the wedge test as used is shown schematically in Figure 1. It is assumed that the aluminium beam is effectively undeformable compared with the composite and supple epoxy. Also, under the conditions studied of small (epoxy)-beam flexion, and with its Young's modulus being much greater than that of the adhesive, we take it that any composite strain remains in the linear, elastic domain. Tests were effected at ambient temperature and humidity. 


\section{Macroscopic Observations}

In some cases, when the crack front had progressed for some time, several drops of a solution of potassium permanganate $\left(\mathrm{KMnO}_{4}\right)$ were allowed to seep into the region close to the crack front before the assembly was removed from the jig. After the solution dried, the assembly was broken open in order to observe the shape of the crack front from the pattern of dyeing by $\mathrm{KMnO}_{4}$.

Another technique was also used to investigate crack front shape. In this case, the composite (opaque) was replaced by a poly(methylmethacrylate) (PMMA) transparent block before the cleavage test. In this way, the crack front shape could be observed directly through the PMMA [11, 12].

\section{Speckle Interferometry}

Speckle interferometry is related to holography and is exceedingly sensitive for the measurement of small, relative displacements of surfaces and therefore strains or deformations of materials. The speckle effect was recognised long ago by Isaac Newton [13], when observing the twinkling of stars. Speckle Interferometry involves, as the name suggests, the interference of light beams. It took on a new dimension, both literally and metaphorically, in the 1960s with the evolution of lasers. A laser beam is projected onto a flat (but not polished) surface and generates a shiny, grainy spot [14]. Analysis of the laser light leads to the association of the speckle phenomenon with the diffusion of coherent light by an optically rough surface [15]. The work of Goodman provides a complete study of the statistical properties of the speckle effect [16], and it has been recently revised by Lehmann [17].

Various forms of speckle effect exist-but, for the present application, we consider subjective speckle, shown schematically in Figure 2, the principle of which is briefly described below. Using an optical bench setup, a continuous wave (CW) $2 \mathrm{~W}$, YaG laser (Verdi Coherent Inc., Santa Clara, CA, USA) producing light of wavelength, $\lambda$, of $532 \mathrm{~nm}$ is projected onto the composite beam of the adhesion assembly (on the left of the figure). Since the surface is (optically) rough, the laser light, imaged by an optical system, gives rise to a speckle spatial distribution by diffraction (on the right of the figure). Point $\mathrm{P}_{1}$ produces a diffraction pattern centred on $\mathrm{P}_{1}^{\prime}$, with a light distribution around $\mathrm{P}^{\prime}{ }_{1}$ (described by a Bessel function of order 1 for a circular aperture, or a sinc function for a rectangular aperture, for instance). Considering a second point, $\mathrm{P}_{2}$, close to $\mathrm{P}_{1}$, it also produces a diffraction pattern centred on $\mathrm{P}_{2}^{\prime}$ but interfering with that of $\mathrm{P}_{1}^{\prime}$. In the case shown, the first minimum of the diffraction pattern at $\mathrm{P}^{\prime}{ }_{2}$ corresponds to 


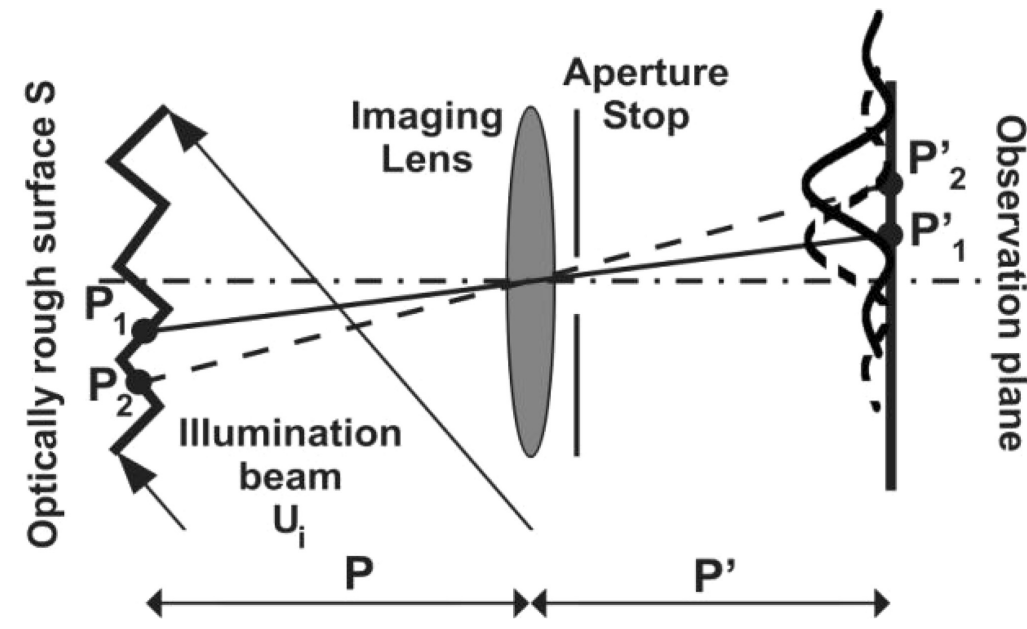

FIGURE 2 Subjective speckle.

$\mathrm{P}^{\prime}{ }_{1}$, and as a consequence, in image space the speckle size is given by $\mathrm{d}_{\mathrm{s}}=2 \times \mathrm{P}_{1}^{\prime} \mathrm{P}_{2}^{\prime}$ :

$$
\mathrm{d}_{\mathrm{s}}=2.44 \frac{\lambda \mathrm{p}^{\prime}}{\mathrm{D}}
$$

where $\mathrm{p}^{\prime}$ is the distance between the lens and the observation plane, $\lambda$ is the light wavelength, and D the aperture stop.

To be able to exploit the speckle pattern thus produced for the whole surface in question, the surface must move slightly. In this case, image correlation is possible and is the optical signature of the surface being studied. Interference of speckle patterns with another beam of coherent light leads to a knowledge of the relative displacement between the surface before and after movement. To get quantitative results, phaseshifting speckle interferometry has to be performed. This requires the recording of at least three specklegrams (a specklegram is an image resulting from interference between a speckle pattern and another beam) for each state of deformation of the object. Phase shift can be effected by slightly displacing the reference beam by some fraction of the light wavelength. The object phase for each state can then be computed and then subtracted to get the displacement. After "unwrapping" (computer treatment of fringe levels to obtain actual relative distances) of the difference phase map and conversion into relative displacement, the desired displacement map can be obtained by taking into account the geometry of the interferometer. An example is shown in Figure 3, 

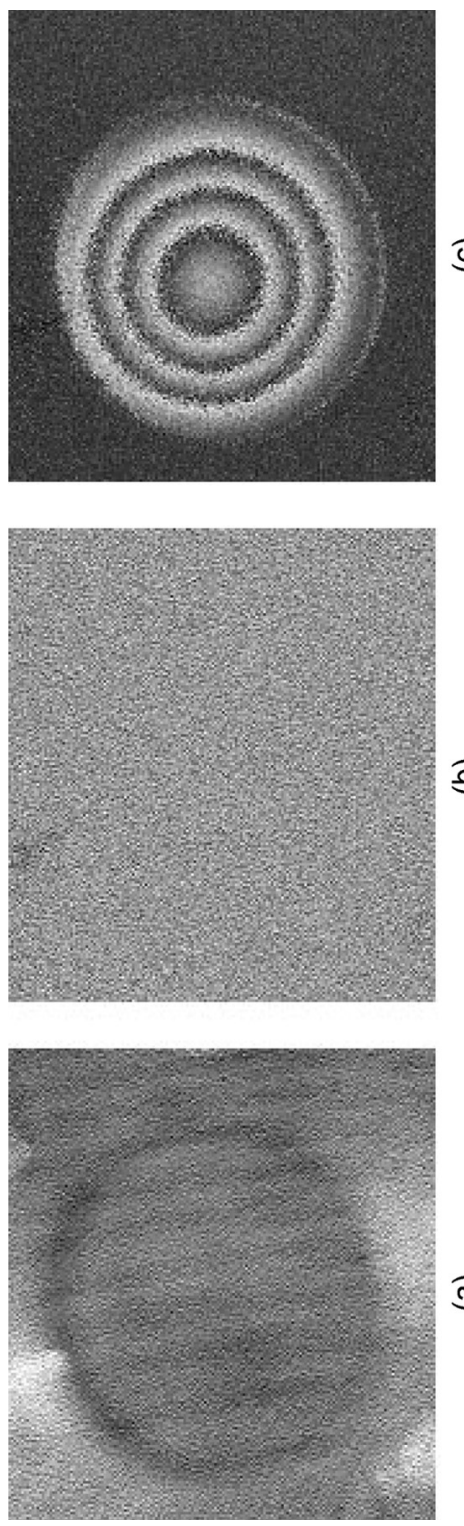

(ิ)
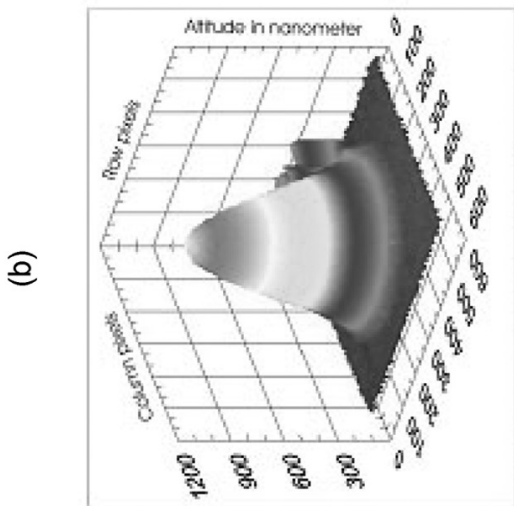

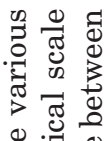

E

$\therefore$.

ज्ञ

㝋

ฮี

淨造

()

त क त

幽

क.

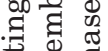

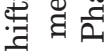

ज

๘ है है

들 ซ్๊

웡

눙 숭

잉

串 क

(1)

ब

ฮี త్ర

की

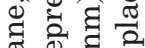

정 है คิ Оㅇㅇㅁ

घี तु $\sigma \Xi$ क फ प्ञ 둴웡

द्व 넝 (1)

跑

2. :-

త్

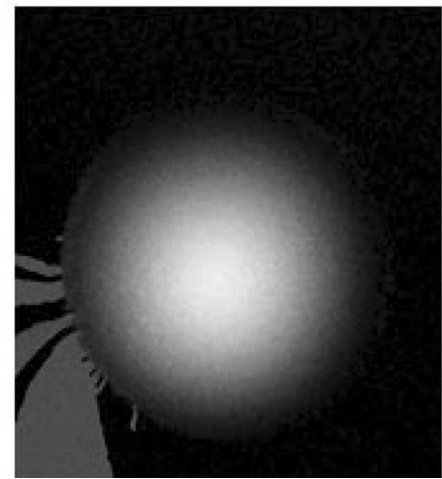

究 क व्व

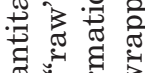

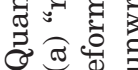

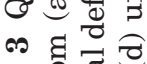

되 뭉 저

될 过 की

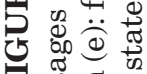

焉施 
corresponding to a deformed membrane. The various steps from "raw" specklegram to final 3D map are shown. For a more complete description of speckle interferometry, which is outside the scope of the present journal, the reader is referred to Slangen and Gautier [18].

In our particular application, the adhesion assembly is set up on an optical bench with the separating wedge already in place. The (slow) crack growth leads to slight displacements of the composite surface, and it is this relative movement that is recorded as a function of time and/or crack-front position using speckle interferometry (in the outof-plane sensitivity configuration).

\section{RESULTS AND INTERPRETATION}

\section{The 2D Calculation of $G_{I C}$}

Since it will be useful below in the interpretation of our results, we shall briefly summarise the calculation leading to $\mathrm{G}_{\mathrm{IC}}$ in the case of one deformable substrate (composite) and one rigid substrate (aluminium) using only the 2D approach. Consider Figure 1 and the classic beam equation $\mathrm{M}=\mathrm{EI} / \mathrm{R}$, where $\mathrm{M}$ is applied moment, $\mathrm{E}$ is Young's modulus of the flexing beam, I its sectional moment of inertia, and $R$ the local radius of curvature. With the Cartesian coordinates shown ( $\mathrm{y}$ is perpendicular to the figure), $\mathrm{M}=\mathrm{Fx}$, where $\mathrm{F}$ is the vertical force exerted on the upper beam by the wedge. We shall neglect the adhesive thickness, $\mathrm{e}$, and since $\mathrm{R}^{-1} \cong \mathrm{z}^{\prime \prime}$ (second differential of $\mathrm{z}$ with respect to $\mathrm{x}), \mathrm{z}^{\prime}(a) \cong \mathrm{z}(a) \cong 0$ at the crack-front $a$, we may integrate to obtain

$$
z(x)=\frac{F}{E I}\left(\frac{x^{3}}{6}-\frac{a^{2} x}{2}+\frac{a^{3}}{3}\right) .
$$

Since $\mathrm{z}(0)=\Delta$, we may eliminate $F, E$, and I to obtain

$$
z(x)=\frac{3 \Delta}{a^{3}}\left(\frac{x^{3}}{6}-\frac{a^{2} x}{2}+\frac{a^{3}}{3}\right) .
$$

The elastic energy stored in the upper beam for $0 \leq x \leq a$ is $\mathrm{M} / 2 \mathrm{R}$ per unit length, and thus the total energy, $\mathrm{U}$, is given by

$$
U=\int_{0}^{a} \frac{M}{2 R} d x=\frac{E I}{2} \int_{0}^{a}\left(z^{\prime \prime}\right)^{2} d x=\frac{3 E I \Delta^{2}}{2 a^{3}} .
$$


By definition, the energy release rate is given by

$$
G+\frac{1}{b} \frac{\partial U}{\partial a}=0
$$

during crack growth, noting that $\mathrm{b}$ is sample width. Since $\mathrm{I}=\mathrm{bh}^{3} / 12$ for a rectangular section, we obtain

$$
G=\frac{3 E \Delta^{2} h^{3}}{8 a^{4}} .
$$

Here $G$ is assumed to correspond essentially to mode I failure, and at fracture a critical value is relevant, thus $G=G_{I C}$. Note the difference of a factor of 2 when compared with Equation (1) since only one beam is flexed (although $\Delta$ has the same definition). $\mathrm{G}_{\mathrm{IC}}$ may then be identified with the energy of adhesion, W.

\section{Observation of Crack Front and Energy of Adhesion}

Note from Equation (8) that the value of $\mathrm{G}_{\mathrm{IC}}$ is very sensitive to crack length, $a$, depending on $a^{-4}$. Using the standard theory of the propagation of errors and defining errors on $\mathrm{G}$ and $a$, respectively, as $\delta \mathrm{G}_{\mathrm{IC}}$ and $\delta a$, it is readily seen that:

$$
\frac{|\delta G|}{G}=\frac{4|\delta a|}{a} .
$$

As a consequence, care must be taken in ascertaining $a$ for use in Equation (8).

The results of macroscopic observation of crack fronts, both by $\mathrm{KMnO}_{4}$ seepage and in the model assembly using PMMA as a substrate, show the same overall features: the crack front is curved and not straight, thus $a$ does not have a constant value over the sample width. This curvature is concave with respect to the direction of propagation of the crack, and so there is no question of the observation being related to some artefact or diffusional process occurring from the environment, which would give a "television screen" effect with rounded corners, but in the convex sense. An example of the failure surface features of the composite side of the assembly after $\mathrm{KMnO}_{4}$ staining is shown in Figure 4. It can be seen that there is a difference, $\mathrm{d} a$, of $c a .2 \mathrm{~mm}$ between the position of the crack front at the centre and that at the edge. What effect does this have on fracture energies?

Using the setup described previously, with the wedge inserted at a distance of $12 \mathrm{~mm}$, crack growth occurs relatively quickly initially and decelerates as time passes. From values of $a(\mathrm{t})$ at time $\mathrm{t}, \mathrm{G}_{\mathrm{IC}}$ may be 

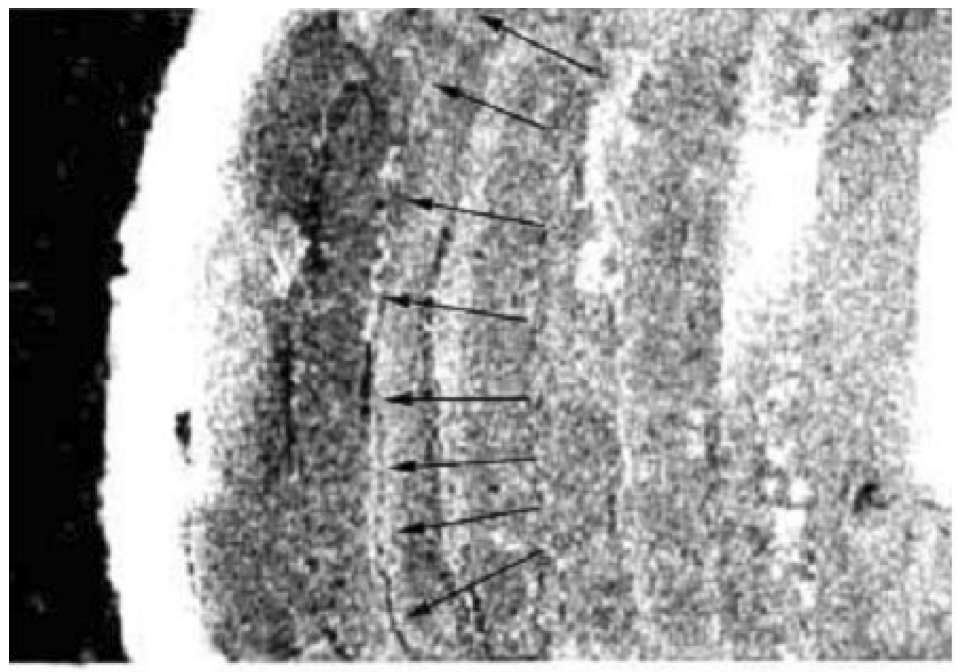

$-2 \mathrm{~mm}$

FIGURE 4 Curved pattern of crack front at different degrees of fracture (arrows show an example). Crack progresses from right to left.

calculated from Equation (8) and crack speed, v, = da/dt. Figure 5 presents $\mathrm{G}_{\mathrm{IC}}\left(\mathrm{Jm}^{-2}\right)$ as a function of $\mathrm{v}\left(\mathrm{mmh}^{-1}\right)$, the latter being on a logarithmic scale. (These results correspond to an aged sample: 35 days at $35^{\circ} \mathrm{C}$ in distilled water.) The solid points represent $\mathrm{G}_{\mathrm{IC}}$ as calculated from the value of $a$ taken at the assembly edge(s), and the open points correspond to $a$ evaluated from the centre of the sample, as estimated by measurements of visible deformations on the millimetric scale and by the $\mathrm{KMnO}_{4}$ coloured area. In both cases, the usual, expected decrease of $\mathrm{G}_{\mathrm{IC}}$ with crack speed, $\mathrm{v}$, is observed due to reduced energy dissipation effects [19], but this is not the major subject of discussion here. What is more significant is that by using the estimated values of $a$ at the centre of the joint (not normally observable under standard conditions), the calculated value of $\mathrm{G}_{\mathrm{IC}}$ is considerably lower: of the order of $40 \% *$ ! Indeed, for most of the samples tested a difference of $c a .2 \mathrm{~mm}$ was found both from the scale deformation and from the $\mathrm{KMnO}_{4}$ pattern. Thus, the distinction

$* N$. B. As the crack length increases, this error will decrease since the bending moment, and therefore the principal curvature, will decrease. This in turn will reduce the anticlastic tendency and allow the fracture front to become straighter. However, errors of the order of tens of per cent are still expected unless the crack length is unmanageably long. 


\section{$\mathrm{G}_{\mathrm{IC}}\left(\mathrm{J} \cdot \mathrm{m}^{-2}\right)$}

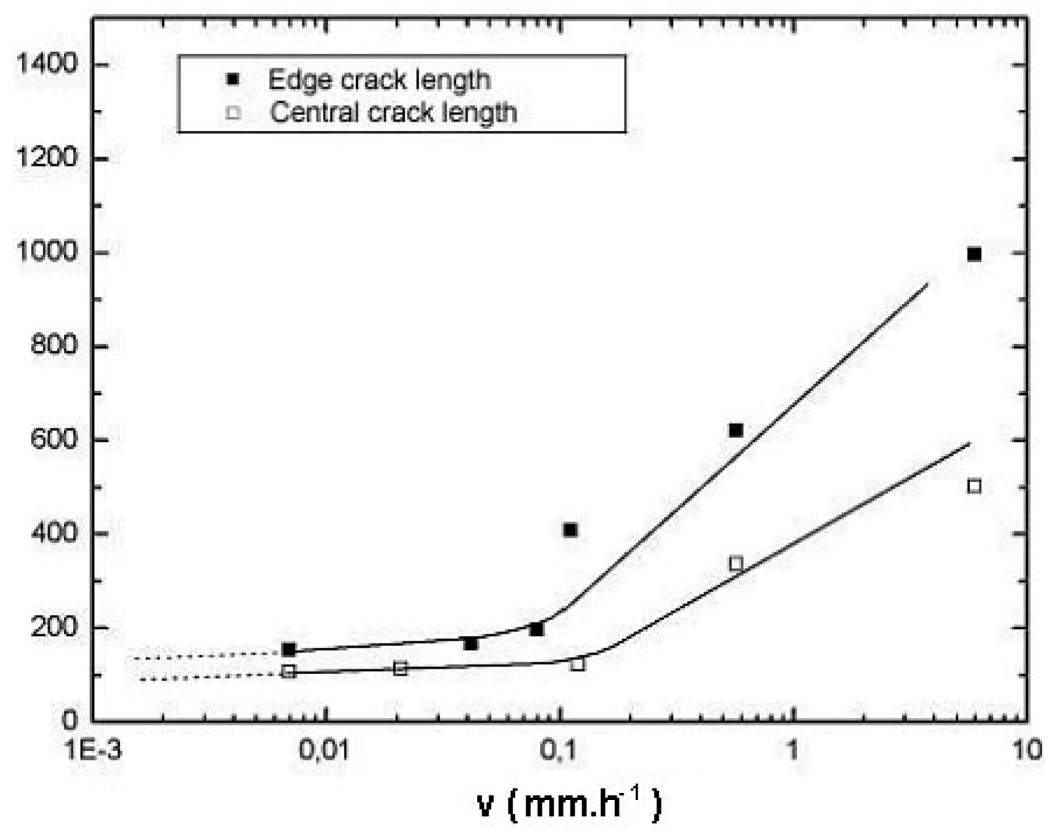

FIGURE 5 Estimation of $\mathrm{G}_{\mathrm{IC}}$ (for an aged sample) depending on whether crack length is estimated at edge or centre of composite/aluminium structure.

between $a(\mathrm{y}=0)$ and $a(\mathrm{y}= \pm \mathrm{b} / 2)$, where $\mathrm{y}$ is the remaining Cartesian coordinate measuring distance from the joint centre line and $b$ is sample width, is important in calculating $\mathrm{G}_{\mathrm{IC}}$. Indeed, at present, the "true" value of $\mathrm{G}_{\mathrm{IC}}$ is still in doubt, but that based on $a(0)$ corresponds to a conservative estimate. Up to now, the observation of the curved crack front is experimental but, in the following we attempt to probe the problem further both by an approximate calculation and use of the sensitive experimental technique of speckle interferometry. It should perhaps be added here that other recent work has shown the curved fracture front phenomenon, but it seems to have been little discussed [11, 20-24].

\section{Approximate Estimation of Anticlastic Effect}

The simple experiment with a rubber eraser described above, Equation (2) and the experimentally observed curved fracture fronts in 


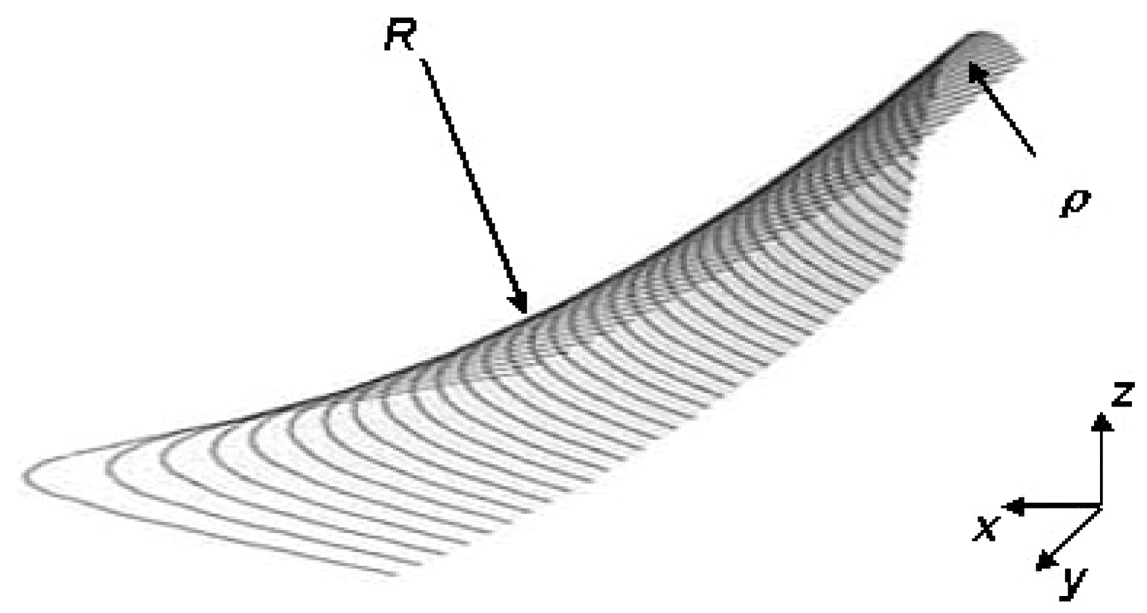

FIGURE 6 Schematic representation of anticlastic curvature.

cleavage seem to point to a common factor; that anticlastic bending cannot be neglected. Some attempts to elucidate its effect in different contexts have been made [8, 25-29], but the problem is not easy. Here we propose a simplified calculation which, admittedly, is inapplicable in the immediate vicinity of the crack-front (the zone of most interest!) but has the advantage of being exploitable in speckle interferometry.

We commence by referring to the $2 \mathrm{D}$ calculation of $\mathrm{G}_{\mathrm{IC}}$ as a basis. In Figure 6, we show a schematic representation of the anticlastic effect to fix one's ideas. Consider Equations (2) and (5), in conjunction with Figures 1 and 6 . If the composite beam is curved concavely with respect to the top, with a radius of curvature $\mathrm{R}(\mathrm{x})$, then we may expect an anticlastic curvature of radius $\rho(x)$ in the plane $(y, z)$, concave towards the bottom, obeying Equation (2). This will be true in the free region of the beam, i.e., removed from the crack front at a distance of ca. $a / 6$ or greater (by St. Venant's principle). Noting that $\mathrm{R}^{-1} \cong \mathrm{z}^{\prime \prime}$, from Equations (2) and (5) we obtain

$$
\rho(x)=\frac{a^{3}}{3 x \Delta v} .
$$

Now consider Figure 7a, which represents a section $(y, z)$ of the composite beam at a given $\mathrm{x}$ (any slight inclination due to curvature in the $(\mathrm{x}, \mathrm{z})$ plane will be negligible). Assuming anticlastic curvature to be 
(a)

b

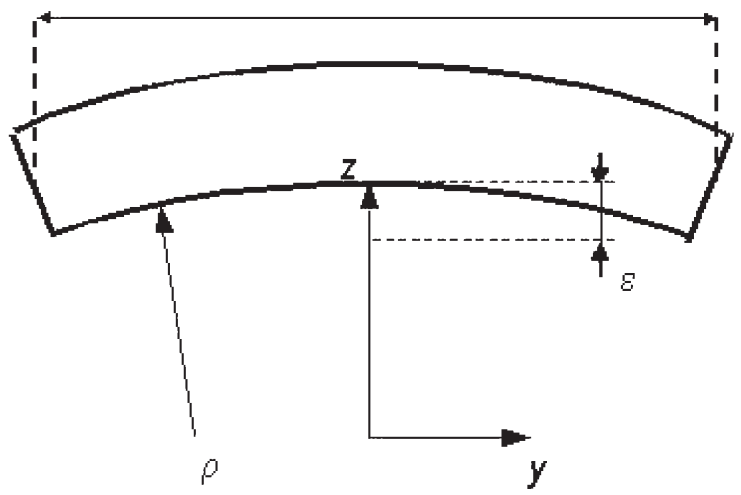

(b)

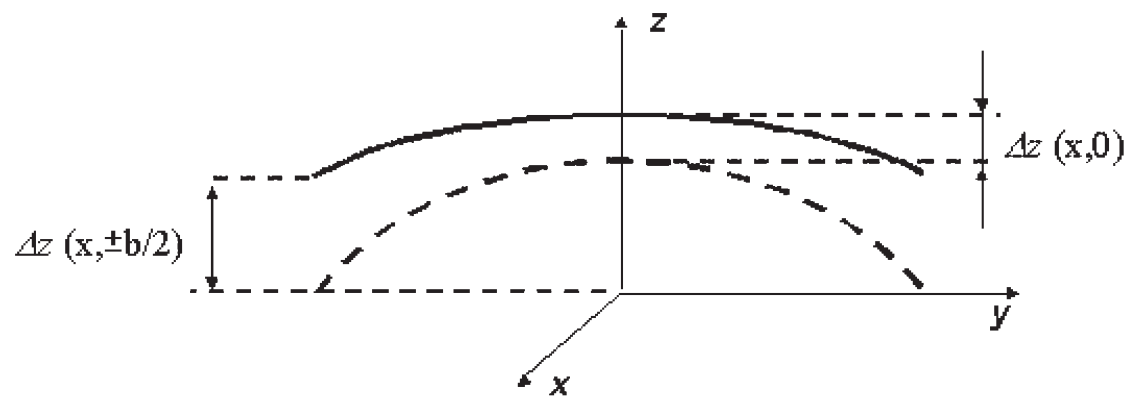

FIGURE 7 (a) Representation of anticlastic bending of composite beam. (b) Anticlastic bending at given $\mathrm{x}$ along beam axis for 2 crack lengths ( $a$ and $a+\delta a$ ). The higher, less-curved profile (continuous line) corresponds to a longer crack length and, therefore, a lower bending moment than the lower (dotted) profile.

weak and taking width, b, and displacement, $\varepsilon$, as, shown in Figure 7a, we have

$$
\varepsilon(x)=\frac{b^{2}}{8 \rho(x)}=\frac{3 b^{2} x \Delta v}{8 a^{3}} .
$$

A decision now has to be made concerning Equation (5): does it apply to the centre of the beam, at $\mathrm{y}=0$, or to the edge(s), at $\mathrm{y}= \pm \mathrm{b} / 2$ (or some intermediate value)? Tentatively, we assume that it applies 
to the centre. Since $\mathrm{z}$ now becomes a function of $\mathrm{x}$ and $\mathrm{y}: \mathrm{z}(\mathrm{x}, \mathrm{y})$, we have

$$
\begin{gathered}
z(x, 0)=\frac{3 \Delta}{a^{3}}\left(\frac{x^{3}}{6}-\frac{a^{2} x}{2}+\frac{a^{3}}{3}\right), \\
z(x, \pm b / 2)=\frac{3 \Delta}{a^{3}}\left(\frac{x^{3}}{6}-\frac{a^{2} x}{2}+\frac{a^{3}}{3}\right)-\frac{3 b^{2} x \Delta v}{8 a^{3}} .
\end{gathered}
$$

This approximate formulation presents mathematical problems near the crack front, because our initial assumption was that of a free beam, and clearly near the adhering zone supplementary stresses are involved due to adhesion itself. A more general form of Equations (12) for $\mathrm{z}(\mathrm{x}, \mathrm{y})$ could be given, but suffice it to treat $\mathrm{z}(\mathrm{x}, 0)$ and $\mathrm{z}(\mathrm{x}, \pm \mathrm{b} / 2)$ here. A schematic 3D representation of the beam undergoing anticlastic bending but without allowing for perturbations near the separation front is given in Figure 8.

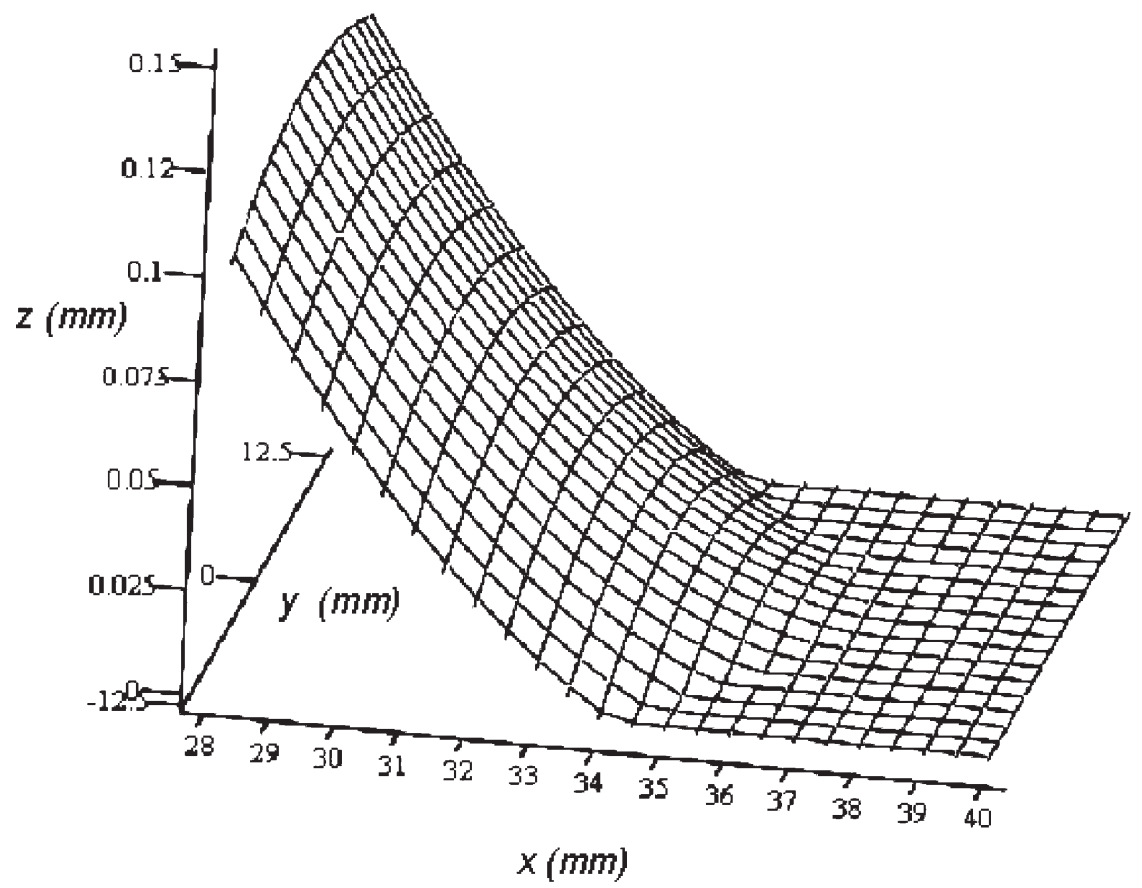

FIGURE 8 Schematic representation of anticlastic bending of curved beam, neglecting perturbing adhesion effects near separation front. 
Now, speckle interferometry involves the detection of relative positions on the (beam) surface, rather then absolute positions. Thus, we consider Equations (12) in the context of a slight crack growth, $\delta a$, leading to displacements of the beam surface. In the present treatment we shall restrict our attention to the (major) displacement in direction $\mathrm{z}$. Of interest is the relative movement of the beam at $\mathrm{z}(\mathrm{x}, 0)$ compared with that at $\mathrm{z}(\mathrm{x}, \pm \mathrm{b} / 2)$ after an incremental increase of crack length, $\delta a$ :

$$
\frac{\partial}{\partial a}[z(x, 0)-z(x, \pm b / 2)] \cdot \delta a=\frac{-9 b^{2} x \Delta v}{8 a^{4}} \cdot \delta a .
$$

In other words, as the crack progresses the outer edges of the beam rise up more than the centre, as shown schematically in Figure $7 \mathrm{~b}$. This effect is due to a reduction of principal bending moment, leading in turn to a reduction in anticlastic bending, and it corresponds to what is observed by speckle interferometry in the free section of the beam.

\section{Application of Speckle Interferometry}

Results were taken from test specimens set up in the speckle interferometer bench. The out-of-plane displacements of the composite beam external face were measured. The following paragraph deals with the discussion of this measurement.

Acquisition started when the wedge stopped. Time between two acquisitions was increased as the crack propagation rate decreased. Figure 9 shows the "wrapped" phase difference induced by the relative composite out-of-plane movement, $24 \mathrm{~h}$ after wedge insertion. The increment of time between 2 acquisitions was $20 \mathrm{~min}$. In this figure, continuous lines of the same grey level indicate the same relative displacement. The out-of-plane configuration of the speckle interferometer induces a displacement between two consecutive fringes of half of the laser wavelength, $\lambda$. In the optical bench used, an interfringe is equivalent to a $266 \mathrm{~nm}$ shift, and the uncertainty of the measurement is $c a .50 \mathrm{~nm}$ due to background noise.

The crack was monitored on the sample side $24 \mathrm{~h}$ after the wedge was stopped. The length from the blade edge to the apparent crack front was $30 \mathrm{~mm}$. Apparently, the crack was cohesive in the composite near the interface between composite and adhesive. The length of the perturbed zone, $a_{p}$, (i.e., the length containing the fringe pattern) induced by insertion of the blade was $40 \mathrm{~mm}$. There is, thus, an apparent difference between the value of $a$ measured on the side of the sample and that by speckle interferometry. This is quite plausible. Indeed, the composite beam could shift and pull the adhesive without 


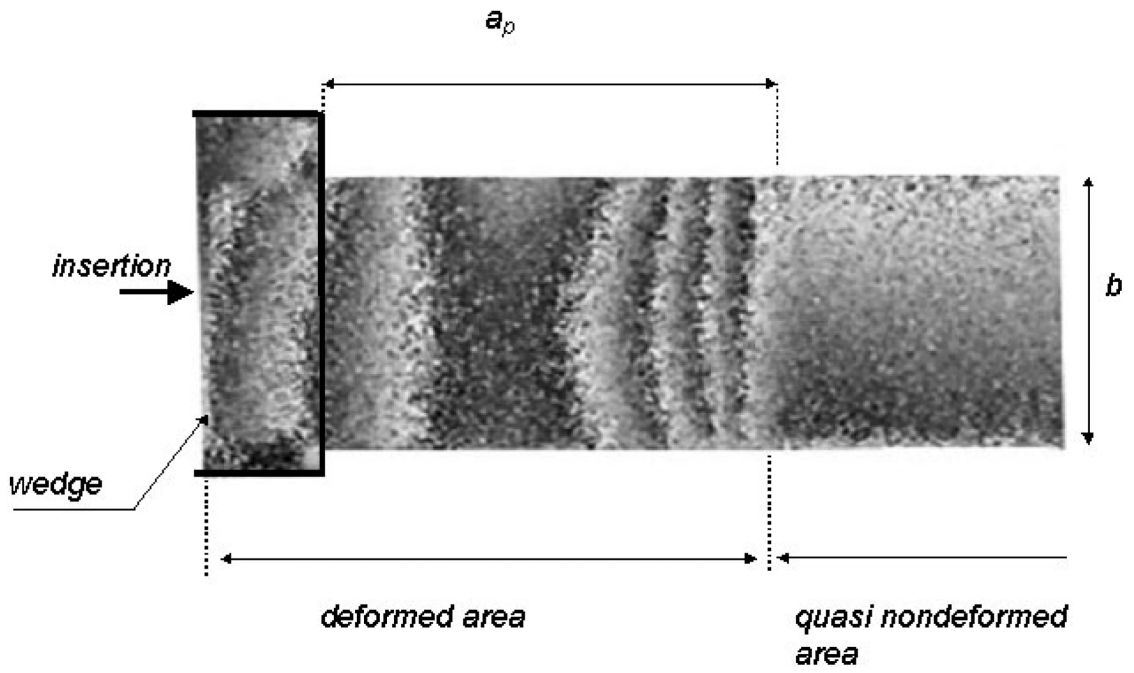

FIGURE 9 Fringe pattern taken $24 \mathrm{~h}$ after wedge insertion with a time interval of $20 \mathrm{~min}$.

real debonding. The real crack, optically measured, appears when the shift exceeds the maximum elongation of the adhesive (see Figure 10).

After several weeks, the apparent length of the crack, optically measured on the side, was $40 \mathrm{~mm}$, confirming that a viscous timedependent phenomenon or pull-out of polymer chains occurs ahead of the crack front, leading to final interfacial debonding.

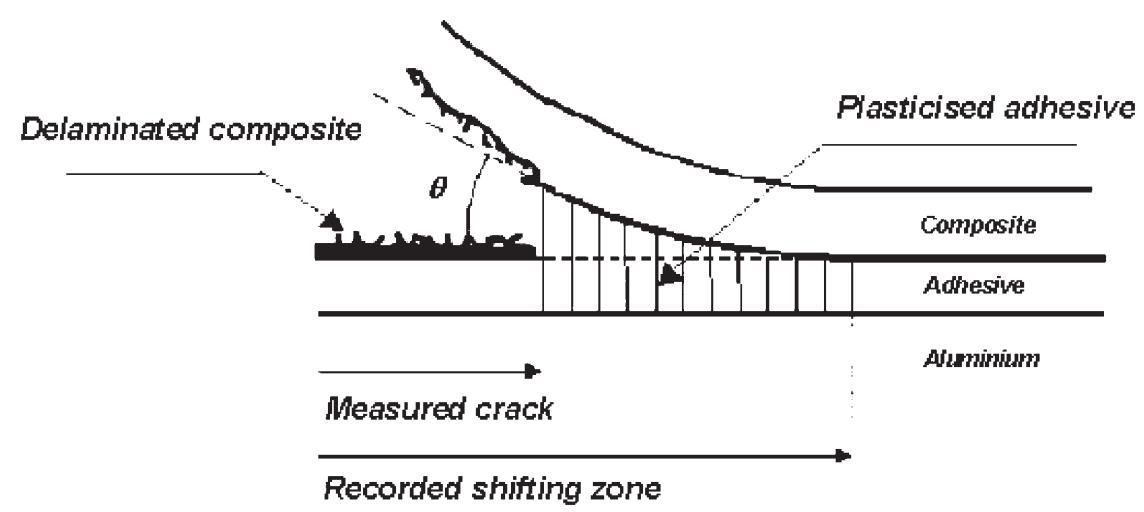

FIGURE 10 Schematic representation of proposed intermediate zone between intact composite/aluminium structure and total separation. 
A second important observation is the regular curved aspect of most of the fringes. It clearly shows that there is a relative movement along the $y$ axis that causes a gradual out-of-plane (along the $z$ axis) shift of the composite beam. This cannot be considered as an "edge effect" confined to the sample sides. Near the crack opening front (COF) zone, the fringes are quite straight. This seems in contradiction with former experimental results, but this point will be discussed further.

After phase "unwrapping" of speckle data, a map of the composite beam external surface out-of-plane displacements was obtained, taking into account the photographic scale. Figure 11 shows the shifting $\Delta z$ in an increment of time $\Delta t(\Delta t=40 \mathrm{~min})$ versus the position of this point along the $x$ axis along the centre line $(y=0)$ and the side line $(y=b / 2) 24 \mathrm{~h}$ after wedge insertion.

The experimental measurements confirm that there is only a part of the composite that is deformed. In $40 \mathrm{~min}$, a relative shift of $500 \mathrm{~nm}$ or

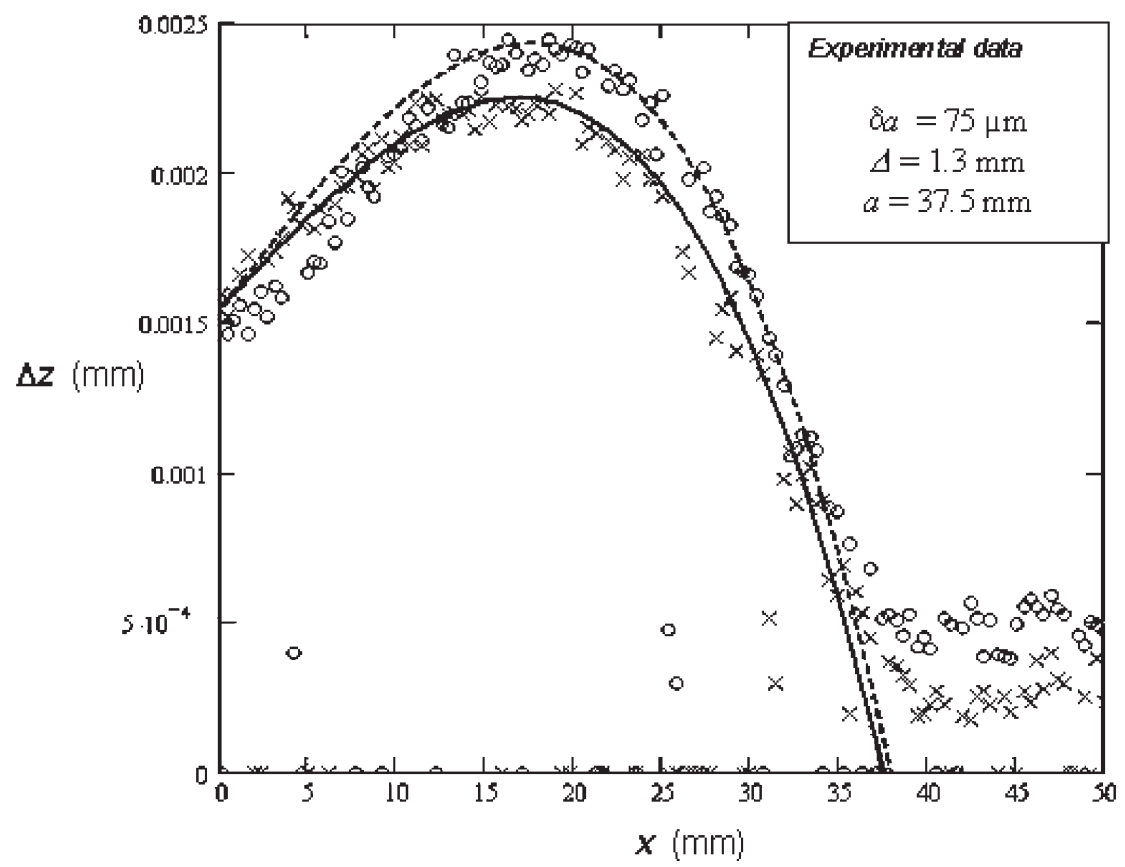

FIGURE 11 Shifting of the composite beam, $24 \mathrm{~h}$ after wedge insertion with a time interval of $\Delta t=40 \mathrm{~min}$ : ( $\mathrm{x}$ ) experimental data for the centre line; (o) experimental data for the side line; (-) calculated for centre line; (- - -) calculated for side line. 
less is measured in the upstream sector of the crack (the theoretical static zone). From the wedge position, the maximum in $\Delta z$ occurs at $x \approx 0.5 . a_{p}$ and the shift decreases to almost zero far from the wedge. The experimental values also clearly show a greater upward shift on the side (o symbol) than the centre ( $\mathrm{x}$ symbol), the difference being about $100 \mathrm{~nm}$ at the maximum, despite the dispersion.

The nonzero shift at $x=0$ should be discussed. Indeed, the calculation considers that the shift at $x=0$ is zero. This is clearly not the case in our experiment. High forces exerted on the inserted wedge might cause slow tilt of the setup, despite fixing that is rigid, to a good (macroscopic) approximation.

The shifting after an increment of time calculated from Equations (12a) and (12b) and corresponding to a crack length increment of $\delta \mathrm{a}$ gives

$$
\begin{gathered}
\Delta z(x, 0)=\frac{3 \cdot \Delta \cdot \delta a}{2 \cdot a^{2}} \cdot\left(x-\frac{x^{3}}{a^{2}}\right)+T(x), \\
\Delta z\left(x, \pm \frac{b}{2}\right)=\frac{3 \cdot \Delta \cdot \delta a}{2 \cdot a^{2}} \cdot\left(x-\frac{x^{3}}{a^{2}}+\frac{3 \cdot b^{2} \cdot v \cdot x}{4 \cdot a^{2}}\right)+T(x),
\end{gathered}
$$

where $\mathrm{a}$ is the crack length (measured a posteriori in the centre) and $T(x)$ is a function introduced to take into account any shifting of the whole setup, where

$$
T(x)=\beta \cdot(1-x / a),
$$

with $\beta$ being the $\Delta z$ value at $x=0$.

It should be noted that Equation (14b) is valid only for $\mathrm{z}(x, \pm b / 2)>0$ due to the incompressibility of the aluminium sheet.

The maximum displacement along $x$ for $y$ constant is given for

$$
\frac{\partial[\Delta z(x, y)]}{\partial x}=0 .
$$

From Equations (14) and (16) and neglecting $\mathrm{T}(\mathrm{x})$, which is only a rotation, we obtain

$$
\begin{gathered}
\frac{\partial[\Delta z(x, 0)]}{\partial x}=\frac{3 \cdot \Delta \cdot \delta a}{2 \cdot a^{2}} \cdot\left(1-\frac{3 \cdot x^{2}}{a^{2}}\right) \\
\frac{\partial[\Delta z(x, \pm b / 2)]}{\partial x}=\frac{3 \cdot \Delta \cdot \delta a}{2 \cdot a^{2}} \cdot\left(1-\frac{3 \cdot x^{2}}{a^{2}}+\frac{3 \cdot b^{2} \cdot v}{4 \cdot a^{2}}\right) .
\end{gathered}
$$


These equations suggest that the maximum of $\Delta z$ is at $c a . x=0.58 . a$ for the centre line $(\mathrm{y}=0)$ and $x$ slightly greater than 0.58. $a$ for the side line $(\mathrm{y}= \pm b / 2)$.

The curves corresponding to Equations (14a) and (14b) are drawn in Figure 11.

In the earlier discussion (see the section "Approximate Estimation of Anticlastic Effect"), we assumed that the centre line (along the $x$ axis) follows the classic equation of deformation for a beam in flexion. This hypothesis seems justified because we observe good agreement between experimental measurements and the curve corresponding to Equation (14a). Between $x=0$ and $x=15 \mathrm{~mm}$, there is an apparent disagreement between the theoretical curve given by Equation (14b) and the experimental measurements corresponding to displacements of the edge. This is the region close to the crack-opening wedge, and this latter may introduce some perturbations. For $\mathrm{x}>15 \mathrm{~mm}$, Equation (14b) describes the edge displacements quite satisfactorily. However, in practice $\delta \mathrm{a}$ is rather difficult to estimate, and the value of $\Delta z$ is very sensitive to it. Figure 11 seems to confirm that the maximal out-of-plane displacement occurs near 0.5. $a_{p}$.

At this stage of the work, only tentative ideas can be offered to explain the difference between experiment and our simple mathematical model. As we assumed anticlastic curvature, curved fringes in the $\mathrm{COF}$ zone may be expected, but in this zone Figure 9 shows straight fringes. The first possibility is that the difference of shifting rate between the edge lines and the centre line may be so small in this region that it is occulted by the background noise, and only global deformation is recorded. Figure 11 shows less shifting than predicted. The second possibility is that the adhesive bonding "works" against the anticlastic curvature and attempts to "maintain" the beam straight on the aluminium substrate from one side to the other, leading to smaller shifting and a straighter COF. In the case of poor adhesion, modelling geometry and shifting could possibly be done as if a virtual surface (as shown in Figures 6 and 8) meets a plane and rigid surface. In the case of high adhesion properties, the area affected by strain and stress leads to a more complex modelling of deformation and shifting. However, far from the COF direct observation of the fringe pattern and measured shifting indicate that there are two distinct types of bending behaviour of the composite beam, depending on the lateral position (along the $y$ axis) of the elementary width unit $d y$ chosen. This transverse phenomenon could be reasonably linked with anticlastic bending. The present work shows that there is indeed a zone in the sample that is strongly affected by wedge insertion and a second one that is almost insensitive to the cleavage. Future work will 


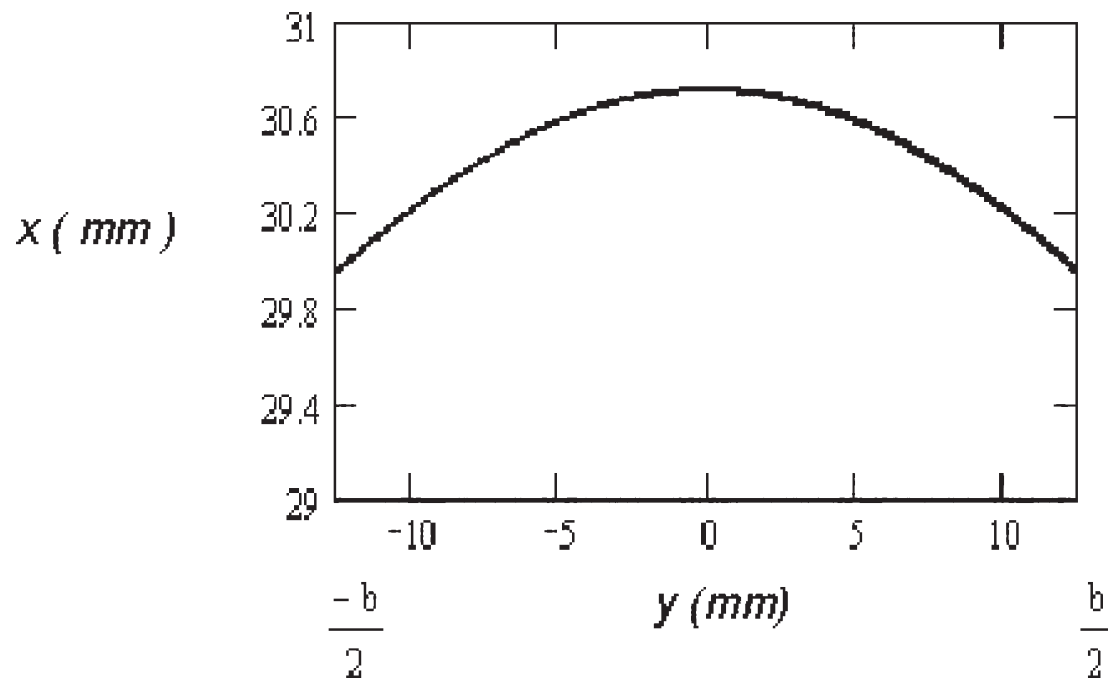

FIGURE 12 Calculated COF assuming adhesive plasticisation.

be done focusing on the $\mathrm{COF}$ zone to enhance the spatial resolution without changing the measurement sensitivity. Moreover, reducing composite beam thickness may enhance the transverse curvature [30] and allow curved fringes in the COF zone to be photographed.

In the case of poor adhesion, if the adhesive plasticisation and deformation $\left(\varepsilon_{\max } \cong 30 \%\right.$ !) is taken into account, i.e., $a=a_{p}$, the equation of the intersection of the deformed surface and plasticised adhesive with thickness, $e$, on the rigid aluminium adherend defined by $a(y)$ is

$$
\frac{3 \Delta}{a^{3}}\left(\frac{a^{3}(y)}{6}-\frac{a^{2} \cdot a(y)}{2}+\frac{a^{3}}{3}\right)-\frac{3 y^{2} a(y) \Delta v}{8 a^{3}}=\varepsilon_{\max } \cdot e .
$$

If we replace symbols with experimental data, we obtain the COF aspect shown in Figure 12. Equation (18) leads to $d a=a(0)$ $-\mathrm{a}( \pm b / 2)=0.8 \mathrm{~mm}$. This is clearly in the range of experimental measurements (see Figure 4).

More-accurate experiments and more-refined calculations have to be done, but these simplified geometric considerations lead to encouraging results.

\section{CONCLUSION}

The adhesion of relatively rigid adherends has often been successfully studied using the wedge test. However, the relatively simple analysis 
of this geometry to obtain fracture energy is $2 \mathrm{D}$. We have studied a composite/epoxy/aluminium system and, both by a $\mathrm{KMnO}_{4}$ dyeing technique and by replacing the composite with a transparent adherend, observed a curved crack front, presumably related to the relatively unrecognised effect of anticlastic bending of the flexible beam. Since a curved crack front implies a variable crack length and the dependence of adhesive energy on this parameter is very sensitive, questions may be asked about the validity of $\mathrm{G}_{\mathrm{IC}}$ values obtained from crack length measurements taken directly from the sample edges. In the present case, a reduction of $c a .40 \%$ is suspected compared with calculations based on the central crack-front length. The "true" value is open to question. Clearly, the $2 \mathrm{D}$ approach is insufficient and further work on the $3 \mathrm{D}$ approach is necessary.

The highly sensitive technique of speckle interferometry was developed and applied to the present wedge test, enabling confirmation of the anticlastic bending of the flexible beam(s) during crack propagation. Agreement between the theory developed for regions far from the crack front and speckle interferometry results is good. However, work is required for a better assessment of behaviour near the crack front and, therefore, for a better estimation of fracture energy.

\section{REFERENCES}

[1] Benbow, J. J. and Roesler, F. C., Proc. Phys. Soc. B70, 201-211 (1957).

[2] Ripling, E. J., Mostovoy, S., and Patrick, R. L., Mat. Res. Stan. 4, 129-134 (1964).

[3] Wiederhorn, S. M., Shorb, A. M., and Moses, R. L., J. Appl. Phys. 39, 1569-1572 (1968).

[4] Mostovoy, S. and Ripling, E. J., J. Appl. Polym. Sci. 13, 1083-1111 (1969).

[5] Hashemi, S., Kinloch, A. J., and Williams, J. G., Proc. R. Soc. 427, 173-199 (1990).

[6] Digby, R. P. and Packham, D. E., Int. J. Adhesion Adhesives 15, 61-71 (1995).

[7] Rider, A. N. and Arnott, D. R., Int. J. Adhesion Adhesives 20, 209-220 (2000).

[8] Sener, J.-Y., Ferracin, T., Caussin, L., and Delannay, F., Int. J. Adhesion Adhesives 22, 129-137 (2002).

[9] Hutchinson, J. W. and Suo, Z., in Advances in Applied Mechanics, J. W. Hutchinson and T. Y. Wu (Eds.) (Academic Press, Boston, 1992), Vol. 29, pp. 63-191.

[10] H. Kuhn and D. Medlin, Eds., ASM-Handbook, (ASM International, Metals Park, OH, USA), Vol. 8, pp. 109-110 (2000).

[11] Al-Khanbashi, A., Petiau, C., Hamdy, A. E., and Moet, A., J. Adhesion Sci. Technol. 17, 1093-1107 (2003).

[12] Sener, J.-Y. and Delannay, F., Int. J. Adhesion Adhesives 21, 339-348 (2001).

[13] Newton, I., in Optics, Book 1 (1652), p. 1730.

[14] White, A. D. and Rigden, J. D., Proceedings of the IRE, 50, p. 1967 (1962).

[15] Allen, L. and Jones, D. G. C., Phys. Lett. 7, 15 (1963).

[16] Goodman, J. W., in Laser Speckle and Related Phenomena, J. C. Dainty, (Ed.) (Springer-Verlag, Berlin, 1984), pp. 9-75. 
[17] Lehmann, T., PhD Thesis, EPFL, Lausanne (Switzerland) (1998).

[18] Slangen, P. and Gautier, B., in Speckle Metrology, K. Gastinger, O. Lokberg, and S, Winther (Eds.) (SPIE, Bellingham, WA, USA), Vol. 4933, pp. 76-81 (2003).

[19] Gent, A. N. and Petrich, R. P., Proc. Roy. Soc. A 310, 433-448 (1969).

[20] Chen, B., Dillard, D. A., Dillard, J. G., and Clark, J. R. L., J. Adhesion 75, 405-434 (2001).

[21] Zhang, S., Panat, R., and Hsia, K. J., J. Adhesion Sci. Technol. 17, 1685-1711 (2003).

[22] Imanaka, M., Takeuchi, Y., Nakamura, Y., Nishimura, A., and Iida, T., Int. J. Adhesion Adhesives 21, 389-396 (2001).

[23] Bader, M. G., Hamerton, I., Hay, J. N., Kemp, M., and Winchester, S., Composites: Part A 31, 603-608 (2000).

[24] Davy, G., Hashemi, S., and Kinloch, A. J., Int. J. Adhesion Adhesives 9, 69-76 (1989).

[25] Davidson, B. D. and Shapery, R. A., J. Comp. Mat. 22, 640-656 (1988).

[26] Davidson, B. D., J. Comp. Mat. 24, 1124-1137 (1990).

[27] Davidson, B. D., Krüger, R., and König, M., Comp. Sci. Technol. 54, 385-394 (1995).

[28] Sun, C. T. and Zheng, S., Comp. Sci. Technol. 56, 451-459 (1996).

[29] Sutton, M. A., Dawicke, D. S., and Newman Jr., J. C., Frac. Mech. 26, 243-255 (1995).

[30] De Morais, A. B., Composites: Part A 35, 51-57 (2004). 